\title{
A REPRESENTAÇÃO DO PARTICIPANTE “TRADUTOR/ TRANSLATOR” EM TRANSLATORS THROUGH HISTORY E OS TRADUTORES NA HISTÓRIA
}

\author{
Lilian Fleuri \\ Universidade Federal de Santa Catarina \\ lilianfleuri@gmail.com
}

Maria Lúcia Vasconcellos Universidade Federal de Santa Catarina marialuciabv@cce.ufsc.br

Adriana Pagano

Universidade Federal de Minas Gerais apagano@ufmg.br

Resumo: Esta pesquisa baseia-se nos conceitos de linguagem e de texto propostos pela Linguística Sistêmico-Funcional (LSF), que interpreta a língua como um sistema modelador de realidades. Insere-se na interface entre a LSF, os Estudos da Tradução e as metodologias dos estudos baseados em Corpus, para a análise da obra Translators Through History (Delisle e Woodsworth, 1995) e sua tradução para o português brasileiro, Os Tradutores na História (trad. Sergio Bath, 2003). Foram examinados os padrões relativos aos Participantes "translator", na textualização, e "tradutor", na retextualização, e dos Processos em que estavam envolvidos, tanto nos paratextos quanto no corpo dos textos selecionados. Os resultados da análise evidenciaram que os padrões emergentes nos paratextos são parcialmente análogos aos padrões do corpo do texto (Participantes "translator" / "tradutor" na função de Ator, Identificado, Portador e Dizente em frequência decrescente), com exceção da função 
Experienciador em Processos Mentais que não ocorre nos paratextos. No que diz respeito à comparação dos padrões no corpo do texto, não foram observadas diferenças relevantes entre a textualizaão e a retextualização. Palavras-chave: Análise textual, tradução, representação do translator, corpus paralelo bilíngue, Tradutores na História, Translators through History.

Abstract: This article reports on an empirical study drawing on Systemic Functional Linguistics (SFL), which sees language as a modeling system of realities. Working at the interface between SFL, Translation Studies (TS) and corpus-based methodologies, it analyzes the volume Translators Through History and its retextualization in Brazilian Portuguese $O s$ Tradutores na História. Patterns regarding the choice of Participants construed through the lexical items "translator/tradutor" were examined both in paratext and text selections. Results showed analogous patterns in paratexts and text (translator and tradutor being construed as Actor, Carrier, Identified, Experiencer and Sayer in a decreasing frequency of occurrence), the sole exception being the non-occurrence of "translator/ tradutor" as Participants of Mental Processes (Senser) in the paratext. As regards the patterns in the texts, no relevant differences were found when comparing the textualization and its retextualization.

Keywords: Text analysis and translation, representation of 'translator'/ 'tradutor', parallel bilingual corpus, Translators through History, Tradutores na História.

\section{Introdução}

Esta investigação ${ }^{1}$ é desenvolvida na recente tradição de pesquisa em Estudos da Tradução (ET), na interface entre os Estudos da Tradução, Linguística Sistêmico-Funcional (LSF) e Estudos da Tradução Baseados em Corpora (ETBC) (cf. Pagano e Vasconcellos, 2005). A base teórica para a análise é o modelo da LSF proposto por Halliday e Mathiessen, 2004. A base metodológica é informada pelos ETBC, conforme definido por Baker (1995) e Olohan (2004). 
Segundo Joly (apud Deslile e Woodsworth, 1995, p.11), “A tradução não pode ser dissociada da ideia do progresso, há mesmo quem sustente que uma sociedade pode ser avaliada pela qualidade das traduções que aceita, o que indica a importância do trabalho dos tradutores" 2 . Não há dúvida, diante desta afirmação, do valor do papel que os tradutores assumem na sociedade. É sobre esses "modestos artesãos da comunicação" (Joly, ibidem) em que esta pesquisa se apóia. Para chegar a uma interpretação com base textual, o estudo examina a realização do Participante tradutor pelos itens lexicais "translator/tradutor", na obra dedicada a eles, elaborada por Jean Deslile e Judith Woodsworth em 1995, Translators Through History e traduzida para o português brasileiro em 2003 por Sérgio Bath, Os Tradutores na História. Analisa-se, neste artigo, o modo como o 'tradutor' - enquanto entidade textual - é representado no texto-original (aqui denominado textualização) e no texto-alvo (aqui denominado retextualização).

$\mathrm{O}$ estudo busca contribuir para o entendimento das formas de representação do tradutor - em termos das premissas semióticas de LSF - no próprio ambiente da tradução. Nesse contexto, a análise busca um cotejamento no que tange aos níveis da léxico-gramática e semântica concentrando a atenção nos itens lexicais "translator" e "tradutor", cujos resultados são, posteriormente, considerados em relação ao nível do contexto de situação. Segundo Tymoczko (2002), o pesquisador pode olhar para o fenômeno da tradução sob a perspectiva de "duas ordens infinitas", ou seja, uma visão macro (contextual) e uma outra visão micro (textual e de base linguística) sobre a tradução. Nessa perspectiva, é possível inserir o texto-alvo em seu "contexto de situação" (Halliday, 1989, p.03), o que corresponderia à visão macro sobre o texto, enquanto se examinam as realizações lexicogramaticais desse texto, adotando-se a visão micro da análise. Conforme Van Gorp (1985, p.46) "Os dados das estratégias micro-estruturais levam a um renovado confronto com as estratégias macro-estruturais e assim às suas considerações em termos do contexto sistêmico mais amplo" ${ }^{3}$. Realiza-se, assim, 
um estudo comparativo do elemento micro-estrutural (lexical), o "translator" e o "tradutor", dentro do complexo oracional ${ }^{4}$.

\section{A interface da pesquisa}

A interface entre ET e LSF tem sido explorada nas últimas décadas por pesquisadores internacionais e brasileiros. Segundo Pagano e Vasconcellos (2005), nos anos 80, a possibilidade de exploração profícua dessa interface já é mencionada por Newmark (1988), em um artigo que discute o uso LSF em análises e críticas de traduções. No início dos 90, Estudos de Tradução de base Sistêmico-Funcional começaram a surgir no âmbito internacional com publicações de estudiosos como Van Leuven-Zwart (1989/1990), Hatim e Mason (1990), Bell (1991), Baker (1992), Gallina (1992), Johns (1992), Malmkjaer (1998), Hale (1997), Zhu (1993). A partir do avanço nas tecnologias computacionais, no início dos anos 2000, a abordagem foi enriquecida pela estrutura metodológica dos estudos de corpus, sobretudo com o apoio de softwares específicos para a investigação de grandes quantidades de textos dispostos eletronicamente. Os estudos de Munday (2002) e de Gouveia e Bárbara (2003) são ilustrações relevantes desse estágio. A utilização de metodologias de corpus nos ET é estabelecida com a publicação do artigo de Olohan (2004); a investigação da linguagem da tradução, com base nas categorias da LSF é consolidada na publicação da obra de Malmkjaer (2005),

No contexto brasileiro, os anos 90 testemunharam um crescente interesse no uso da LSF nos ET. No início dos anos 2000 esse interesse se renovou com a integração de metodologia e técnicas em corpus, presente em pesquisas realizadas por universidades brasileiras. Entre elas, encontram-se a Universidade Federal de Minas Gerais (UFMG) e a Universidade Federal de Santa Catarina (UFSC), que emergiram como núcleos de pesquisas, explorando tal modalidade de pesquisa, no âmbito da pós-graduação, 
conforme documentado em Pagano e Vasconcellos (2005) e Vasconcellos (2009).

A concentração do engajamento Sistêmico-Funcional com ET em ambas as universidades brasileiras pode ser explicada pelo desenvolvimento de um projeto em conjunto dos programas de pós-graduação PosLin (UFMG) e PGI (UFSC), com o apoio da CAPES, por meio do 'Programa Nacional de Cooperação Acadêmica - PROCAD' (097/10-2), que esteve em vigor de julho de 2001 a dezembro de 2005. Nesse contexto, interfaces interdisciplinares foram propostas para iluminar o fenômeno tradutório, com o suporte teórico da LSF. Os pesquisadores trabalhando em tal interface acabaram por se tornar os impulsionadores da conjunção LSF e ET, a que vieram por incorporar as metodologias de estudos baseados em corpus.

No que tange a Linguística Sistêmico-Funcional, esta pesquisa focaliza mais especificamente o Sistema da Transitividade, que realiza a metafunção experiencial da linguagem, a qual desempenha um importante papel na maneira como textos e suas traduções podem representar 'realidades': nesse processo, segundo Munday (2002), "os padrões de transitividade são frequentemente alterados no texto de chegada" (idem, p.85). O autor chama a atenção para a produtividade da análise da LSF dos textos-fonte e alvo para determinar "aspectos importantes que têm sofrido mudanças na tradução" (idem, p.89). No que tange a aspectos metodológicos, a investigação se beneficia da dinamização do processo de pesquisa possibilitada por softwares, no presente caso, WordSmith Tools (Scott, 1999), com suas ferramentas Concord e Viewer and Aligner.

A Figura 1 abaixo permite visualizar a inserção do trabalho na interface: 


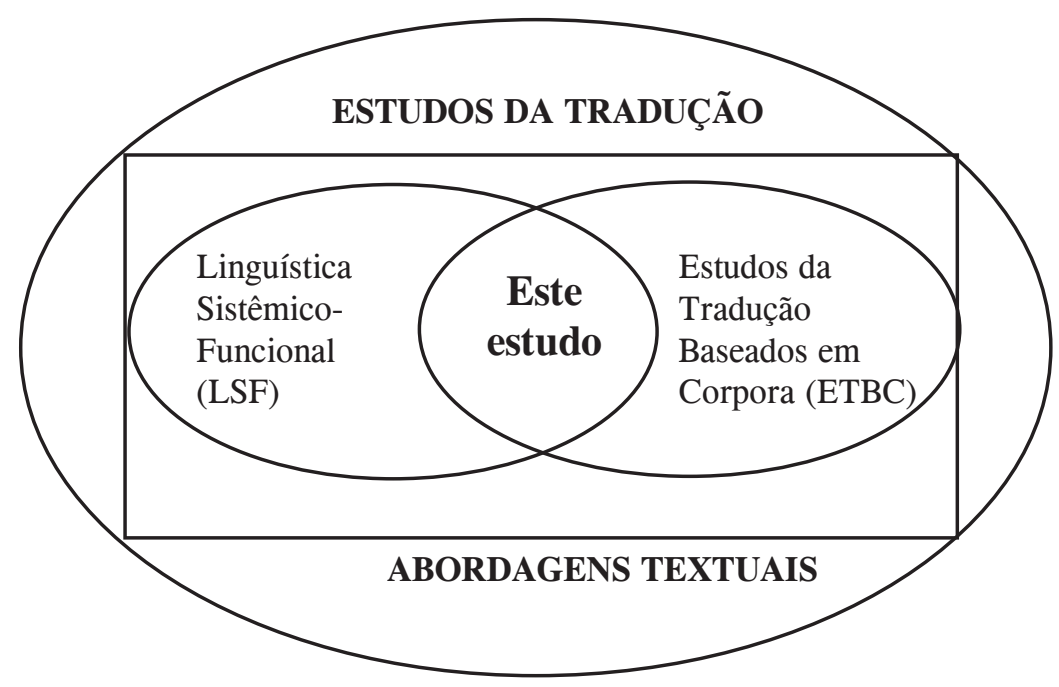

Figura 1: Arcabouço teórico-metodológico: explorando interfaces em paradigmas complementares.

A pergunta de pesquisa que motiva o trabalho é baseada na afirmativa de Munday (2002), segundo a qual, tipicamente, ocorrem novas construções nos padrões de transitividade na tradução; nessa linha, presume-se que na retextualização, o item lexical 'tradutor' entrará em nova configuração ideacional, produzindo novas representações no contexto do português brasileiro. Busca-se, assim, verificar como e onde elas ocorrem, comparando-se a textualização e a retextualização. Para tanto, o software WordSmith Tools vem a auxiliar o processo da pesquisa, por possibilitar o levantamento de dados compilados a partir do corpus bilíngue de pequena dimensão. Esperase, assim, identificar as orações em que o termo "translator" e "tradutor" funcionam enquanto Participantes e realizar a análise das escolhas de transitividade dentro do contexto de ambas as produções, traçando nessas o perfil do uso dos itens lexicais que constroem os Participantes. 
Desta forma, a pesquisa vem para ilustrar um modo possível de proceder análise textual em ET, operando na interface entre a LSF e Estudos da Tradução Baseados em Corpora.

\section{A Metodologia}

Nesta seção, organizada com base em Fernandes (2004) e detalhada em Fleuri (2006), encontram-se os procedimentos metodológicos adotados na preparação do corpus, assim como sua descrição. A seção de metodologia é organizada em dois principais estágios: (3.1) o estágio de construção, processamento do corpus e procedimentos de análise e (3.2) o estágio de desenho, onde se descrevem o corpus e seu contexto textual.

\subsection{Construção, processamento do corpus e procedimentos de análise}

Nesta pesquisa separamos a metodologia em dois grandes blocos: (i) a metodologia de análise do corpus e (ii) a metodologia de preparação do corpus.

$\mathrm{Na}$ metodologia de análise é delimitada a unidade e o objeto de análise. Esta metodologia foi guiada pelas categorias fornecidas pela Gramática Sistêmico-Funcional, discutidas por Halliday e Matthiessen (2004), Halliday (1985 e 1994), Martin et al. (1997) e Eggins (1994).

A unidade de análise selecionada é o complexo oracional ${ }^{5} \mathrm{em}$ que se encontra o objeto de análise, que, como mencionado anteriormente, consiste dos itens lexicais "translator" e "tradutor" e seus respectivos elementos $\operatorname{coesivos}^{6}$ no interior desse complexo oracional. Os itens lexicais "translator/tradutor" devem ser núcleos do Grupo Nominal, Participantes de Processos. Portanto, todo e qualquer item lexical "translator" e "tradutor" na função de modificador de um núcleo nominal não foi considerado na análise. 
Apenas casos como no exemplo (1) foram analisados, enquanto os casos como no exemplo (2) foram desconsiderados ${ }^{7}$ :

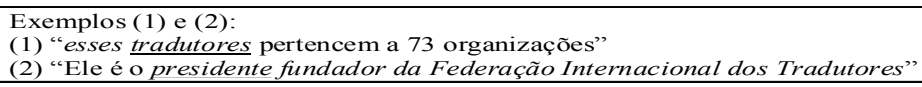

Os itens lexicais "translator/tradutor" foram analisados dentro da cadeia coesiva (elipses e elementos anafóricos e catafóricos) de cada complexo oracional em que estavam inseridos. Todos esses elementos foram identificados e rotulados com os códigos do CROSF15, o que permitiu seu processamento no WordSmith Tools para fornecer os dados que permitissem interpretar o papel do Participante realizado pelos itens lexicais "translator/tradutor".

O CROSF15 ${ }^{8}$ é um Código de Rotulação Sistêmico-Funcional, desenvolvido por Feitosa (2005, p.144). O CROSF15 facilita a busca no corpus eletrônico, permitindo a visualização e a contagem dos dados analisados através do WordSmith Tools que, por meio do Concord, realiza a busca automática de todas as ocorrências. Um rótulo é composto por uma sequência de 7 algarismos inseridos entre parênteses angulares, correspondendo aos seguintes elementos metafuncionais, respectivamente: (1) “Tema/Rema”, (2) "Posição", (3) “Metafunção", (4)marcação, (5) Metafunção Ideacional, Interpessoal ou Textual; (6 e 7) tipos de categorias da definida metafunção (nesta pesquisa: Processo ${ }^{9}$ ou Participante. Categorias não contempladas ou não explícitadas são marcadas com o dígito 0 (zero). O Exemplo 3 ilustra o uso do CROSF15 nesta pesquisa. No exemplo abaixo o $\langle *\rangle$ indica que o Participante não foi analisado, pois "tradutor/translator" não é núcleo do Grupo Nominal:

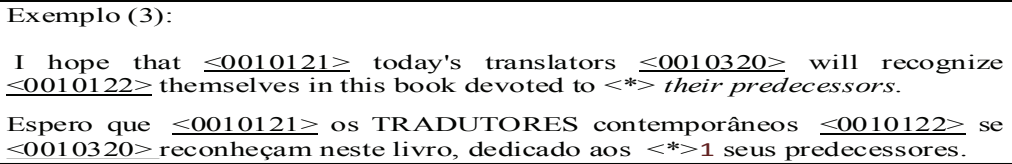


Como neste estudo é realizada uma investigação das estruturas do Sistema de Transitividade que realiza a Metafunção Ideacional, os quatro primeiros números são fixos, havendo mudança dos últimos três conforme a classificação de cada Participante e Processo, pois se referem aos componentes estruturais do Sistema de Transitividade.

Após a rotulação, o documento é convertido em .txt para ser compatível com o ambiente do WordSmith Tools. O WordSmith Tools é um software de análise textual para a investigação de textos dispostos em formato eletrônico. A ferramenta Concord é utilizada para observar a concordância dos nódulos (tradut* e translat*) e para buscar o número de ocorrências de cada rótulo ${ }^{10}$.

Portanto, o refinamento do elemento de análise (itens lexicais "translator/tradutor", núcleo de um grupo nominal, Participante de Processo, e sua cadeia coesiva dentro do Complexo Oracional) e o modo de proceder a rotulação desses elementos, a partir da utilização do CROSF15, e de operar o software de concordância, WordSmith Tools, definem as etapas metodológicas de construção do corpus.

\subsection{O corpus: descrição e contexto}

Translators Through History (Deslile e Woodsworth, 1995) e Os Tradutores na História (trad. Sérgio Bath) formam o corpus desta pesquisa, classificado como corpus paralelo bilíngue de pequena dimensão de acordo com definições oferecidas por Olohan (2004), Baker (1998), Sardinha (2004) e Sinclair (2001). O corpus é “paralelo", porque o texto original é comparado, lado a lado, com sua tradução (Olohan, 2004); "bilíngue", pois o inglês e o português são as duas únicas línguas envolvidas (Baker, 1995) e de "pequena dimensão", não apenas pelo aspecto quantitativo (Sardinha, 2004), mas, sobretudo, por suas características em relação ao modo de intervenção do investigador (Sinclair, 2001): o corpus é construído previamente pelo pesquisador, após definição dos objetivos da pesquisa e a intervenção da pesquisadora em termos da anotação do corpus é entendida como "Intervenção Humana Prévia" (nossa tradução de 'Early Human Intervention' - EHI). 
Produzido com o objetivo de "lembrar aos tradutores o passado recente e remoto" e de "ilustrar a importância que tiveram na evolução do pensamento" (Deslile e Woodsworth, 1995, p.11), Translators Through History, com publicações simultâneas em inglês e francês (Les Traducteurs dans l'histoire), realiza um grande resgate histórico das atuações e contribuições dos tradutores ao longo do tempo em diversas partes do mundo, como Europa, Américas, Oriente Médio, África e Ásia. Esta obra foi traduzida para o português, em 2003 (Os Tradutores na História) e para o espanhol (Los Traductores en la Historia) pela Editorial Universidad de Antioquia, em 2005.

A Figura 4 abaixo mostra ilustrações das capas da $13^{a}$ edição da textualização (em inglês) e da $1^{\text {a }}$ edição da retextualização (para o português brasileiro).

TEXTO DE PARTIDA

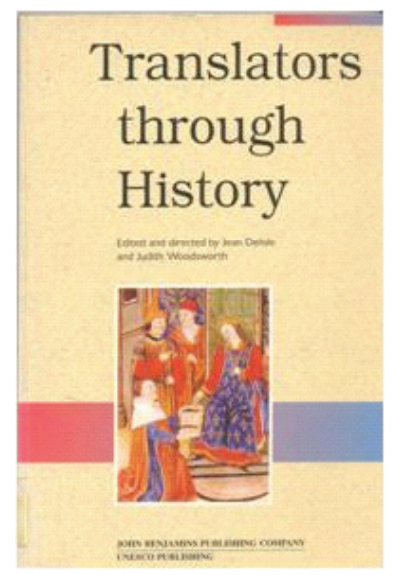

\section{TEXTO DE CHEGADA}

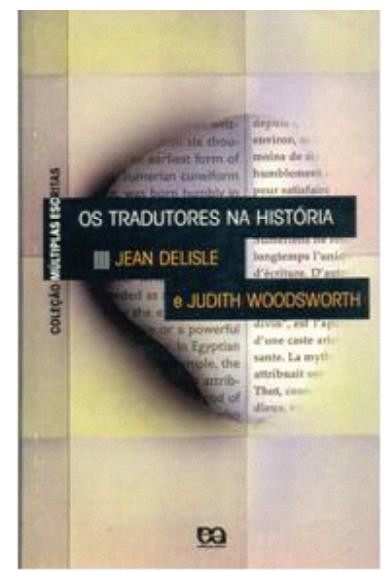

Figura 2: Capa dos livros da $13^{\mathrm{a}}$ edição e da $1^{\mathrm{a}}$ edição de Translators Through History e de Os Tradutores na História, respectivamente.

Ambas as obras são compostas por um prefácio, escrito por Jean-François Joly, uma introdução, escrita por Jean Delisle and Ju- 
dith Woodsworth, e nove capítulos, sob a responsabilidade de "um grupo internacional de historiadores, liderado por um autor principal" (idem, p.15). Os capítulos se apresentam da seguinte forma:

\begin{tabular}{|c|c|c|}
\hline Capítulos Textualização & Capítulos Retextualização & Organizadores/escritores \\
\hline $\begin{array}{l}\text { 1. Translators and the } \\
\text { invention of alphabets }\end{array}$ & $\begin{array}{l}\text { Os tradutores e a invenção } \\
\text { de alfabetos }\end{array}$ & Jean Delisle \\
\hline $\begin{array}{l}\text { 2. Translators and the } \\
\text { development of } \\
\text { national languages }\end{array}$ & $\begin{array}{l}\text { Os tradutores e o } \\
\text { desenvolvimento das } \\
\text { línguas nacionais }\end{array}$ & Charles Atangana Nama \\
\hline $\begin{array}{l}\text { 3. Translators and the } \\
\text { emergence of national } \\
\text { literatures }\end{array}$ & $\begin{array}{l}\text { Os tradutores e a } \\
\text { emergência das literaturas } \\
\text { nacionais }\end{array}$ & Judith Woodsworth \\
\hline $\begin{array}{l}\text { 4. Translators and the } \\
\text { dissemination of } \\
\text { knowledge }\end{array}$ & $\begin{array}{l}\text { Os tradutores e a } \\
\text { disseminação do } \\
\text { conhecimento }\end{array}$ & Myriam Salama-Carr \\
\hline $\begin{array}{l}\text { 5. Translators and the } \\
\text { reins of power }\end{array}$ & Os tradutores e o poder & André Lefevere \\
\hline $\begin{array}{l}\text { 6. Translators and the } \\
\text { spread of religions }\end{array}$ & $\begin{array}{l}\text { Os tradutores e a difusão } \\
\text { das religiões }\end{array}$ & Sherry Simon \\
\hline $\begin{array}{l}\text { 7. Translators and the } \\
\text { transmission of cultural } \\
\text { values }\end{array}$ & $\begin{array}{l}\text { Os tradutores e a } \\
\text { transmissão dos valores } \\
\text { culturais }\end{array}$ & Yves Gambier \\
\hline $\begin{array}{l}\text { 8. Translators and the } \\
\text { writing of dictionaries }\end{array}$ & $\begin{array}{l}\text { Os tradutores e os } \\
\text { dicionários }\end{array}$ & Henri Van Hoof \\
\hline $\begin{array}{l}\text { 9. Interpreters and the } \\
\text { making of history }\end{array}$ & $\begin{array}{l}\text { Os intérpretes que fizeram } \\
\text { história }\end{array}$ & Margareta Bowen \\
\hline
\end{tabular}

Figura 3: Ilustração dos títulos de cada capítulo da textualização e da retextualização e respectivos organizadores.

Desta forma, a obra apresenta um grande painel, organizado por temas, do "principais papéis exercidos pelos tradutores ao longo do tempo" (idem, ibdem), seja inventando alfabetos, colaboran- 
do para o enriquecimento das línguas, estimulando a formação das literaturas nacionais, agindo em instâncias do poder, disseminando o conhecimento técnico e científico, difundindo religiões e também redigindo dicionários. Os "Nove temas foram selecionados para refletir as diferentes áreas nas quais o trabalho dos tradutores foi mais visível" (idem, ibdem).

Os dados coletados são extraídos do Prefácio, Introdução e dos cinco primeiros capítulos. Além disso, foi observada a construção dos itens "translator/tradutor" nas contracapas das obras envolvidas, com o intuito de observar as construções prévias à leitura da obra de tais Participantes.

\section{Análise e Resultados}

Nesta seção serão exploradas separadamente a análise de um tipo de paratexto (a contracapa) na textualização e retextualização, na subseção 4.1 , e a análise dos dados rotulados no interior da obra, na seção 4.2. Os procedimentos metodológicos descritos na seção anterior são aplicados apenas na análise apresentada na seção 4.2, sendo a análise das contracapas realizada manualmente.

\subsection{Análise de Paratexto: Contracapas}

Contracapas, segundo Genette (1982, p.10), configuram-se como paratexto. "Pode-se dizer que os paratextos apresentam duas principais funções: informar e influenciar o leitor" ${ }^{11}$. (Kovala, 1996). Nesta pesquisa, as contracapas, além de contextualizar o leitor ao corpus estudado, fornecem elementos prévios de análise do Participante tradutor, podendo mostrar como o Participante "translator/tradutor" é representado na textualização e na retextualização, antes mesmo da leitura da obra completa. Essa análise é, ao contrário da análise do corpus, realizada sem o auxílio do WordSmith Tools. 
Nesse espaço, instalam-se as perguntas de pesquisa do presente estudo, que buscam verificar até que ponto a representação do Participante "translator/tradutor", sugerida na contracapa, é realmente construída no corpo da obra. Para tal fim, analisa-se primeiramente a contracapa da textualização (Texto 1) e, em seguida, a contracapa da retextualização (Texto 2).

Texto 1: Contracapa da textualização

In $A D$ 629, a Chinese monk <Pro.Relacional> named $<$ Part.Identificado $>\underline{\text { Xuan Zang }<\text { Part.Ator }>\underline{\boldsymbol{\varnothing}}<\text { Pro.Material }>\underline{\text { set }}}$

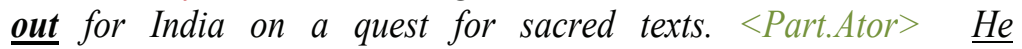
$<$ Pro.Material $>$ returned with a caravan of 22 horses bearing Buddhist treasures and $<$ Part.Ator $>\underline{\varnothing}<$ Pro.Material $>$ spent the last 20 years of his life in the "Great Wild Goose Pagoda", in

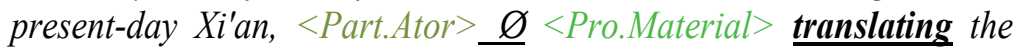
Sanskrit manuscripts into Chinese with a team of collaborators.

In the 12th century, <Part.Ator $>$ scholars <Pro.Material $>$ $\underline{\text { came }}$ to Spain from all over Europe $<$ Part.Ator $>\underline{\varnothing}<$ Pro.Material $>$ seeking knowledge that had been transmitted from the Arab world. Their names tell the story - Adelard of Bath, Hermann of Dalmatia, Plato of Tivoli. Among them <Pro.Relacional> was $<$ Part.Identificado $>$ Robert of Chester (or Robert of Kent), $<$ Part.Portador $>$ who $<$ Pro.Relacional $>$ was part of an elaborate $<$ Part.Ator $>$ team that $<$ Pro.Material $>$ translated documents on Islam and the Koran itself. $<$ Part.Portador $>$ Dona Marina, also $<$ Pro.Relacional $>\underline{\text { called }}$ La Malinche, <Part.Identificado $>\underline{\varnothing}$ $<$ Pro.Relacional $>\underline{\text { was a }}$ crucial link between Cortes and native peoples <Part.Ator $>$ she $<$ Pro.Material $>$ set out to convert and $<$ Part.Ator $>\underline{\varnothing}<$ Pro.Material $>$ conquer in 16th-century Mexico. One of the conquistador's "tongues" or interpreters, $<$ Part.Portador $>$ she <Pro.Relacional> was also the mother of his son. $<$ Part.Portador $>$ She $<$ Pro.Relacional $>$ has been an ambivalent figure in the history of the new world, her own history having been rewritten in different ways over the centuries. 
$<$ Part.Ator $>$ James Evans, an Englishman $<$ Pro.Material $>$ $\underline{\text { sent to evangelize }}$ and $<$ Part.Ator $>\underline{\varnothing}<$ Pro.Material $>$ educate the natives of western Canada during the 19th century, $<$ Part.Ator $>\underline{\varnothing}$ $<$ Pro.Material $>$ invented a writing system in order $\langle$ Part.Ator $\rangle \underline{\varnothing}$ $<$ Pro.Material $>$ to translate and $<$ Part.Ator $>\underline{\varnothing}<$ Pro.Material $>$ transcribe religions texts. Known as "the man $<$ Part.Ator $>$ who $<$ Pro.Material $>$ made birchbark talk", <Part.Ator $>$ he even $<$ Pro.Material $>$ succeeded in printing a number of pamphlets, $<$ Part.Ator $>\underline{\varnothing}<$ Pro.Material $>$ using crude type fashioned out of lead from the lining of tea chests and ink made from a mixture of soot and sturgeon oil. A jackpress used by traders to pack furs served as a press.

These are just some of the stories told in this work, published under the International Federation of Translators (FIT).

Surpreendentemente, o Participante "translator" não é textualizado como tal item lexical nenhuma vez na contracapa da Textualização. Aparece apenas uma vez, no último parágrafo, como modificador do grupo nominal "International Federation of Translators", não sendo portanto considerado em nossa análise. Entretanto a figura de "translator" se encontra representada ao longo de todo o texto, sendo textualizada por nomes próprios e outros designativos da profissão dentro da corrente coesiva. O Processo "translate" em que estão envolvidos e o contexto definem tais elementos como designativos de "tradutores". Se considerarmos como representantes do item lexical "translator" os outros itens lexicais que se referem a tradutor, observa-se seu envolvimento em 24 Processos: 17 Materiais, representados por 17 Participantes Ator; e 7 Relacionais, representados por 4 Participantes Portador e 3 Participantes Identificado. Nos dois primeiros parágrafos os tradutores são identificados como nomes de figuras importantes na história e carregam atributos de sua carreira ou suas realizações. Em todo momento, e exclusivamente no último parágrafo, os tra- 
dutores são representados por seus feitos na história, mostrando a importância a eles conferida em Translators Through History.

$\mathrm{Na}$ contracapa da retextualização, o Participante realizado pelo item lexical "tradutor" apresenta o seguinte perfil ideacional:

\begin{tabular}{|c|}
\hline 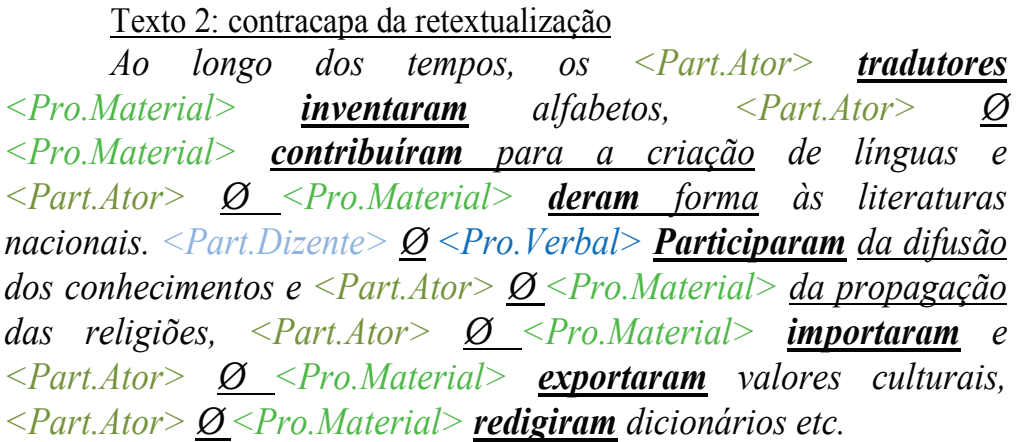 \\
\hline $\begin{array}{l}\quad<\text { Part.Identificado }>\underline{\text { Tradutores e intérpretes }} \text { sempre } \\
<\text { Pro.Relacional }>\text { representaram um papel determinante na evolução } \\
\text { das sociedades e na vida intelectual. Estes são apenas os principais } \\
\text { setores em que }<\text { Part.Ator }>\varnothing<\text { Pro. Material }>\text { atuaram. Traçando } \\
\text { um panorama da importância dessa atividade na Europa, Américas, } \\
\text { África, Índia e China, este livro é leitura indispensável para quem se } \\
\text { dedica aos estudos de tradução e ao mundo das letras. }\end{array}$ \\
\hline
\end{tabular}

O item lexical "tradutor" está envolvido em 10 Processos, sendo 8 deles Materiais e os restantes Relacional e Verbal. Em 80\% das ocorrências, "tradutor" é Ator, em $10 \%$ é Identificado e em outros $10 \%$ é Dizente. Majoritariamente, na contracapa da retextualização, o tradutor é representando como um Participante ativo ${ }^{12}$ envolvido em ações relacionadas à sua profissão e a feitos importantes na humanidade, tais como: inventar alfabetos, ajudar a criar línguas, formar literaturas nacionais importar e exportar valores culturais, redigir dicionários e atuar nesses setores mencionados. Além disso, difundiram o conhecimento. Por esses grandiosos fei- 
tos, eles são identificados como representantes da evolução das sociedades e na vida intelectual.

Os padrões identificados na contracapa da textualização e da retextualização podem ser identificados na Tabela 1 abaixo:

\begin{tabular}{|l|c|c|c|c|}
\hline $\begin{array}{c}\text { TIPO DE } \\
\text { PARTICIPANTE }\end{array}$ & $\begin{array}{c}\text { TOTAL } \\
\text { TEXTUALIZA- } \\
\text { ÇÃO }\end{array}$ & Percentage & $\begin{array}{c}\text { TOTAL } \\
\text { RETEXTUALIZA- } \\
\text { ÇÃO }\end{array}$ & Percentage \\
\hline ATOR & 17 & $71 \%$ & 8 & $80 \%$ \\
\hline IDENTIFICADO & 3 & $12 \%$ & 1 & $10 \%$ \\
\hline PORTADOR & 4 & $17 \%$ & 0 & $0 \%$ \\
\hline DIZENTE & 0 & $0 \%$ & 1 & $10 \%$ \\
\hline TOTAL & $\mathbf{2 4}$ & $\mathbf{1 0 0 \%}$ & $\mathbf{1 0}$ & $\mathbf{1 0 0 \%}$ \\
\hline
\end{tabular}

Tabela 1: Quadro comparativo entre a ocorrência total de Participantes "translator" e "tradutor" nos paratextos da textualização e retextualização.

Dentro de um total de 24 Processos envolvendo o Participante "translator" na textualização, 71\% dos Participantes são Atores, envolvidos em 17 Processos Materiais; $12 \%$ são identificado e outros $17 \%$ são Portador, envolvidos em 7 Processos Relacionais. Na retextualização, em um total de 10 Processos, $80 \%$ dos Participantes são Atores, envolvidos em 8 Processos Materiais; $10 \%$ são Identificado, envolvidos em 1 Processo Relacional e 10\% são Dizentes, envolvido em 1 Processo Verbal.

Os dados encontrados nesses paratextos nos levam a esperar, portanto, que os itens lexicais "translator/ tradutor" são construídos na obra sobretudo como Participantes ativos, envolvidos mais frequentemente em Processos Materiais, Relacionais e Verbais, respectivamente. Espera-se um envolvimento nulo ou mínimo de ambos os itens lexicais em Processos Mentais, Comportamentais ou Existenciais. Os itens lexicais "translator / tradutor" são, pois, Participantes que realizam ações externas, significantes na história e na vida intelectual da sociedade; que disseminam conhecimento ao longo dos tempos; que são identificados, nomeados e qualificados e que disseminaram conhecimento. 


\subsection{Análise dos dados rotulados no interior da obra}

Ao contrário da análise dos paratextos, a análise da obra utilizou procedimentos metodológicos descritos na seção 3: cada item "translator/tradutor" foi etiquetado com o CROSF15 e rastreado e quantificado por meio do WordSmith Tools.

Os dados coletados são extraídos do prefácio, introdução e dos cinco primeiros capítulos da textualização Translators Through History e da correspondente retextualização. Os gráficos expostos abaixo representam os resultados da análise de um total de 415 Processos na textualização e 405 na retextualização. São quatro os Processos predominantes na textualização e na retextualização, como mostra a figura abaixo: Processo Material, Mental, Relacional e Verbal.

\begin{tabular}{|l|c|c|c|c|}
\hline $\begin{array}{c}\text { TIPO DE } \\
\text { PROCESSOS }\end{array}$ & $\begin{array}{c}\text { TEXTUALIZA- } \\
\text { ÇÃO }\end{array}$ & Percentage & $\begin{array}{c}\text { RETEXTUALIZA- } \\
\text { ÇÃO }\end{array}$ & Percentage \\
\hline $\begin{array}{l}\text { MATERIAL } \\
<0010310>\end{array}$ & 205 & $50 \%$ & 213 & $54 \%$ \\
\hline $\begin{array}{l}\text { MENTAL } \\
<0010320>\end{array}$ & 46 & $11 \%$ & 42 & $10 \%$ \\
\hline $\begin{array}{l}\text { RELACIONAL } \\
<0010330>\end{array}$ & 127 & $31 \%$ & 110 & $27 \%$ \\
\hline $\begin{array}{l}\text { VERBAL } \\
<0010340>\end{array}$ & 35 & $8 \%$ & 38 & $9 \%$ \\
\hline $\begin{array}{l}\text { COMPORTA- } \\
\text { MENTAL } \\
<0010350>\end{array}$ & 2 & $0 \%$ & 1 & $0 \%$ \\
\hline $\begin{array}{l}\text { EXISTENCIAL } \\
<0010360>\end{array}$ & 0 & $0 \%$ & 1 & $0 \%$ \\
\hline $\begin{array}{l}\text { TOTAL } \\
<00103 *>\end{array}$ & $\mathbf{4 1 5}$ & $\mathbf{1 0 0 \%}$ & $\mathbf{4 0 5}$ & $\mathbf{1 0 0 \%}$ \\
\hline
\end{tabular}

Tabela 2: Contagem de processos, com o auxílio do WordSmith Tools (Scott, 1999), no interior da Textualização (envolvidos pelo Participante "translator") e Retextualização (envolvidos pelo Participante "tradutor”). 
A partir da leitura da Tabela 2, constatamos que o item lexical "translator", na textualização, encontra-se envolvido majoritariamente em Processos Materiais (50\%) e em Processos Relacionais (31\%). As ocorrências de Processos Mentais, Verbais atingem 19\% dos casos. Os Processos Comportamentais e Existenciais são praticamente nulos. O padrão do item lexical "tradutor", na respectiva retextualização, segue a mesma ordem que a do item "translator" na textualização. Portanto, os Processos em que o Participante "translator/tradutor" se encontram mais envolvidos são os Materiais e Relacionais.

Os Processos Materiais mais frequentes (ocorrendo no mínimo 7 vezes no texto) na textualização são listados a seguir: work (12 ocorrências), contribute (11), translate (10), use (8); e na retextualização, contribuir (11), trabalhar (11), traduzir (8), exercer (7), fazer (7). Pelo tipo de Processo em que o Participante é mais envolvido, observa-se uma relação direta entre essa construção e a profissão de tradutor: ao realizar esse trabalho, o tradutor contribui para desenvolvimento de línguas, de recursos linguísticos e de literaturas, para a circulação de textos, disseminação de conhecimentos, para a introdução de religiões em novos contextos, para mencionar apenas alguns de seus feitos.

Os Processos Relacionais mais frequentes (que ocorrem no mínimo 7 vezes no texto) na textualização são listados a seguir: be (46 ocorrências), have (12), play a role (8), become (7); e na retextualização, ser (29), ter (16) e tornar (9). O Processo Relacional principal e mais frequente, tanto na textualização quanto na retextualização, é o "be/ser", o que frequentemente insere o tradutor em configurações nas quais ele está ou em relação de identificação com outros elementos, ou em relação de atribuição de qualidades (absolutas ou relativas).

A análise evidenciou alguns casos de novas construções de Processos ocorridas na retextualização. Estas alterações de Processos se deram, sobretudo, de três principais formas: (i) o Processo foi retextualizado como uma metáfora gramatical; (ii) o Processo foi 
retextualizado como Participante na configuração ideacional e viceversa; e (iii) um Processo Material causativo é retextualizado como um Processo Relacional.

Certamente essas alterações de Processos causaram as diferenças de representação do Participante "translator/tradutor" entre a textualização e a retextualização, observadas na Tabela 3, abaixo. Os Participantes envolvidos em tais Processos se distribuem na seguinte proporção:

\begin{tabular}{|c|c|c|c|c|}
\hline $\begin{array}{l}\text { TIPO DE } \\
\text { PARTICIPANTE }\end{array}$ & TEXTUALIZAÇÃO & Percentage & $\begin{array}{l}\text { RETEXTUALI- } \\
\text { ZAÇÃO }\end{array}$ & Percentage \\
\hline $\begin{array}{l}\text { ATOR } \\
<0010111>\end{array}$ & 172 & $40 \%$ & 182 & $44 \%$ \\
\hline $\begin{array}{l}\text { META } \\
<0010112>\end{array}$ & 20 & $5 \%$ & 20 & $5 \%$ \\
\hline $\begin{array}{l}\text { RECEBEDOR } \\
<0010113>\end{array}$ & 11 & $3 \%$ & 12 & $3 \%$ \\
\hline $\begin{array}{l}\text { CLIENTE } \\
<0010114>\end{array}$ & 2 & $1 \%$ & 1 & $0 \%$ \\
\hline $\begin{array}{l}\text { EXPERIENCIA- } \\
\text { DOR } \\
<0010121>\end{array}$ & 28 & $7 \%$ & 25 & $6 \%$ \\
\hline $\begin{array}{l}\text { FENÔMENO } \\
<0010122>\end{array}$ & 23 & $5 \%$ & 19 & $5 \%$ \\
\hline $\begin{array}{l}\text { PORTADOR } \\
<0010131>\end{array}$ & 74 & 18 & $66 \%$ & $16 \%$ \\
\hline $\begin{array}{l}\text { ATRIBUTO } \\
<0010132>\end{array}$ & 11 & $3 \%$ & 10 & $2 \%$ \\
\hline $\begin{array}{l}\text { IDENTIFICADO } \\
<0010133>\end{array}$ & 30 & $7 \%$ & 27 & $7 \%$ \\
\hline $\begin{array}{l}\text { IDENTIFICA- } \\
\text { DOR } \\
<0010134>\end{array}$ & 12 & $3 \%$ & 8 & $2 \%$ \\
\hline $\begin{array}{l}\text { DIZENTE } \\
<0010141>\end{array}$ & 24 & $6 \%$ & 23 & $6 \%$ \\
\hline $\begin{array}{l}\text { RECEPTOR } \\
<0010142>\end{array}$ & 8 & $2 \%$ & 11 & $3 \%$ \\
\hline
\end{tabular}




\begin{tabular}{|l|c|c|c|c|}
\hline $\begin{array}{l}\text { VERBIAGEM } \\
<0010143>\end{array}$ & 3 & $1 \%$ & 3 & $1 \%$ \\
\hline $\begin{array}{l}\text { COMPORTAN- } \\
\text { TE } \\
<0010151>\end{array}$ & 2 & $0 \%$ & 1 & $0 \%$ \\
\hline $\begin{array}{l}\text { EXISTENTE } \\
<0010161>\end{array}$ & 0 & $0 \%$ & 1 & $0 \%$ \\
\hline $\begin{array}{l}\text { TOTAL } \\
<\mathbf{0 0 1 0 3}>\end{array}$ & $\mathbf{4 2 0}$ & $\mathbf{1 0 0 \%}$ & $\mathbf{4 1 1}$ & $\mathbf{1 0 0 \%}$ \\
\hline
\end{tabular}

Tabela 3: Frequência de ocorrência dos papéis dos Participantes.

A Tabela 3 aponta para uma configuração do "translator/tradutor" como um Participante majoritariamente ativo, dentro de cada categoria de Processo em que está envolvido. Como os Processos de maior ocorrência são os Materiais e Relacionais, os Participantes ativos são Ator (40\% e 44\%), Portador (18\% e 16\%) e Identificado (7\%), tanto na textualização como na retextualização.

Se os paratextos realmente podem influenciar a leitura e a recepção do texto (Koava, 1996), então a expectativa do leitor seria de encontrar um Participante "translator/tradutor", envolvido majoritariamente em Processos Materiais, Relacionais e Verbais, participando como Ator, Identificado, Portador e Dizente. De fato, em uma proporção diferenciada, essas 4 representações são as formas mais ocorrentes de configuração do Participante "translator/tradutor". Entretanto, no interior da obra, coincidindo com o número de ocorrência do Participante Dizente e Identificado, observa-se a ocorrência do Participante Experienciador, não mencionado em nenhum dos paratextos. Essa característica mostra que, no interior da obra, os itens lexicais "translator" e "tradutor" são representados não apenas como Participantes cujas ações estão relacionadas ao seu trabalho profissional de tradutor (realizadas pelos Processos Materiais), mas também sendo relacionados a personagens que fizeram história (realizados pelos Processos Relacionais) ou comunicando (realizado pelo Processo Verbal), tomando decisões, refletindo e participando cognitivamente de atividades intelectuais (o que é evi- 
denciado por realizações por meio de Processos Mentais).

\subsection{Análise dos dados rotulados no interior da obra}

Ao contrário da análise dos paratextos, que foi realizada manualmente, a análise da obra utilizou procedimentos metodológicos descritos na seção 3. Portanto, cada item "translator/tradutor" foi etiquetado com o CROSF15 e rastreado e quantificado no WordSmith Tools.

Os dados coletados são extraídos do prefácio, introdução e dos cinco primeiros capítulos da textualização Translators Through History e da correspondente retextualização. Os gráficos expostos abaixo representam os resultados da análise de um total de 415 Processos na textualização e 405 na retextualização. São quatro os Processos predominantes na textualização e na retextualização, como mostra a figura abaixo: Processo Material, Mental, Relacional e Verbal.

\begin{tabular}{|l|c|c|c|c|}
\hline $\begin{array}{c}\text { TIPO DE } \\
\text { PROCESSOS }\end{array}$ & TEXTUALIZAÇÃO & Percentage & $\begin{array}{c}\text { RETEXTUALI- } \\
\text { ZAÇÃO }\end{array}$ & Percentage \\
\hline $\begin{array}{l}\text { MATERIAL } \\
<0010310>\end{array}$ & 205 & $50 \%$ & 213 & $54 \%$ \\
\hline $\begin{array}{l}\text { MENTAL } \\
<0010320>\end{array}$ & 46 & $11 \%$ & 42 & $10 \%$ \\
\hline $\begin{array}{l}\text { RELACIONAL } \\
<0010330>\end{array}$ & 127 & $31 \%$ & 110 & $27 \%$ \\
\hline $\begin{array}{l}\text { VERBAL } \\
<0010340>\end{array}$ & 35 & $8 \%$ & 38 & $9 \%$ \\
\hline $\begin{array}{l}\text { COMPORTA- } \\
\text { MENTAL } \\
<0010350>\end{array}$ & 2 & $0 \%$ & 1 & $0 \%$ \\
\hline $\begin{array}{l}\text { EXISTENCIAL } \\
<0010360>\end{array}$ & $\mathbf{4 1 5}$ & $\mathbf{1 0 0 \%}$ & $\mathbf{4 0 5}$ & $\mathbf{1 0 0 \%}$ \\
\hline $\begin{array}{l}\text { TOTAL } \\
<\mathbf{0 0 1 0 3}>\end{array}$ & 0 & & 1 & $0 \%$ \\
\hline
\end{tabular}

Tabela 4: Contagem de processos, com o auxílio do WordSmith Tools (Scott, 1999), no interior da Textualização (envolvidos pelo Participante "translator") e Retextualização (envolvidos pelo Participante "tradutor"). 
A partir da leitura da Tabela 4, constata-se que o item lexical "translator", na textualização, encontra-se envolvido majoritariamente em Processos Materiais (50\%) e em Processos Relacionais (31\%). As ocorrências de Processos Mentais, Verbais atingem $19 \%$ dos casos. Os Processos Comportamentais e Existenciais são praticamente nulos. O item lexical "tradutor", na respectiva retextualização, segue a mesma ordem que a do item "translator". Portanto, os Processos em que o Participante "translator/tradutor" se encontram mais frequentemente envolvidos são os Materiais e Relacionais.

Os Processos Materiais mais frequentes13 (ocorrendo no mínimo 4 ou 3 vezes no texto) foram, na textualização: work (12 ocorrências), contribute (11), translate (10), use (8), give (5), exercise (5) e make (4), draw (4,) go (3), do (3), adapt (3), create (3), introduce (3) e produce (3), e na retextualização, contribuir (11), trabalhar (11), traduzir (8), exercer (7), fazer (7), dar (6), desenvolver (5), escrever (3), criar (3), promover (3), usar (3), utilizar (3). O tradutor é representado principalmente como uma entidade que produz ou que é produto de uma atividade tal como trabalhar, traduzir e fazer. Observa-se também que muita atividade na qual o tradutor está envolvido tem relação com sua profissão que é: traduzir, escrever, adaptar, produzir, elaborar (draw), desenvolver e criar. Em muitos casos, ao realizar esse trabalho, o tradutor contribui no desenvolvimento de línguas, de recursos linguísticos e de literaturas, na circulação de textos, disseminação de conhecimentos, na introdução de religiões, etc.

Os Processos Relacionais mais frequentes (que ocorrem no mínimo 3 vezes no texto), por sua vez, foram, na textualização: be (46 ocorrências), have (12), play a role (8), become (7) e assume the role (3) e na retextualização, ser (29), ter (16), tornar (9), participar (6), estar (4), assumir o papel (3). O Processo Relacional principal e mais frequente, tanto na textualização quanto na retextualização, é o "be/ser", o que indica que o tradutor é frequentemente relacionado, portando ou sendo identificado, a outros 
elementos como qualidades absolutas (exemplo 4, "the first") ou relativas (exemplo 5) ou a seres/pessoas (exemplo 6):

Exemplos 4, 5 e 6:

(4) $<0010133>$ TRANSLATORS themselves $<0010330>$ will undoubtedly be the first $<0010113>\varnothing<0010310>$ to gain from it".

(5) "The first great poets $[\ldots]<0010330>$ were essentially $<0010132>$ TRANSLATORS,$<0010111>\varnothing<0010310>$ writing at a time, when translation, imitation and creation were inextricably bound."

(6) "Sara Austin $(1793-1867)<0010330>$ foi $<0010134>\underline{\text { a primeira }}$ TRADUTORA profissional de importância.".

A análise evidenciou alguns casos de novas construções de Processos ocorridas da textualização para a retextualização. Estas alterações de Processos se deram, sobretudo, de três principais formas: (i) o Processo foi retextualizado como uma metáfora gramatical, como ocorre no seguinte par de sentenças: "[...] a translator holding the reins of Power [...]" retextualizado como "[...] um tradutor que teve poder nas mãos [...]"; (ii) o Processo foi retextualizado como Participante na configuração ideacional e vice-versa, como ocorre nos seguintes pares: "[...] the translators decided to experiment [...]" e "[...] os tradutores decidiram fazer a experiência [...]", e (iii) um Processo Material causativo é retextualizado como um Processo Relacional, como ocorre em: "[...] the translators and revisers [...] who have made it possible to publish $[\ldots]$ " e "[...] tradutores e revisores [...] que tornaram possível a publicação [...].

Essas novas configurações ideacionais explicam as diferenças de representação do Participante "translator/tradutor" entre a textualização e a retextualização, observadas na Tabela 5.

Os Participantes envolvidos em tais Processos se distribuem na seguinte proporção: 


\begin{tabular}{|c|c|c|c|c|}
\hline $\begin{array}{l}\text { TIPO DE } \\
\text { PARTICIPANTE }\end{array}$ & $\begin{array}{l}\text { TEXTUALIZA- } \\
\text { ÇÃO }\end{array}$ & Percentage & $\begin{array}{l}\text { RETEXTUALI- } \\
\text { ZAÇÃO }\end{array}$ & Percentage \\
\hline $\begin{array}{l}\text { ATOR } \\
<0010111>\end{array}$ & 172 & $40 \%$ & 182 & $44 \%$ \\
\hline $\begin{array}{l}\text { META } \\
<0010112>\end{array}$ & 20 & $5 \%$ & 20 & $5 \%$ \\
\hline $\begin{array}{l}\text { RECEBEDOR } \\
<0010113>\end{array}$ & 11 & $3 \%$ & 12 & $3 \%$ \\
\hline $\begin{array}{l}\text { CLIENTE } \\
<0010114>\end{array}$ & 2 & $1 \%$ & 1 & $0 \%$ \\
\hline $\begin{array}{l}\text { EXPERIENCIA- } \\
\text { DOR } \\
<0010121>\end{array}$ & 28 & $7 \%$ & 25 & $6 \%$ \\
\hline $\begin{array}{l}\text { FENÔMENO } \\
<0010122>\end{array}$ & 23 & $5 \%$ & 19 & $5 \%$ \\
\hline $\begin{array}{l}\text { PORTADOR } \\
<0010131>\end{array}$ & 74 & 18 & $66 \%$ & $16 \%$ \\
\hline $\begin{array}{l}\text { ATRIBUTO } \\
<0010132>\end{array}$ & 11 & $3 \%$ & 10 & $2 \%$ \\
\hline $\begin{array}{l}\text { IDENTIFICADO } \\
<0010133>\end{array}$ & 30 & $7 \%$ & 27 & $7 \%$ \\
\hline $\begin{array}{l}\text { IDENTIFICADOR } \\
<0010134>\end{array}$ & 12 & $3 \%$ & 8 & $2 \%$ \\
\hline $\begin{array}{l}\text { DIZENTE } \\
<0010141>\end{array}$ & 24 & $6 \%$ & 23 & $6 \%$ \\
\hline $\begin{array}{l}\text { RECEPTOR } \\
<0010142>\end{array}$ & 8 & $2 \%$ & 11 & $3 \%$ \\
\hline $\begin{array}{l}\text { VERBIAGEM } \\
<0010143>\end{array}$ & 3 & $1 \%$ & 3 & $1 \%$ \\
\hline $\begin{array}{l}\text { COMPORTANTE } \\
<0010151>\end{array}$ & 2 & $0 \%$ & 1 & $0 \%$ \\
\hline $\begin{array}{l}\text { EXISTENTE } \\
<0010161>\end{array}$ & 0 & $0 \%$ & 1 & $0 \%$ \\
\hline $\begin{array}{l}\text { TOTAL } \\
<00103 *>\end{array}$ & 420 & $100 \%$ & 411 & $100 \%$ \\
\hline
\end{tabular}

Tabela 5: Frequência de ocorrência dos papéis dos Participantes 
A Tabela 5 aponta para uma configuração do "translator/tradutor" como um Participante majoritariamente ativo, dentro de cada categoria de Processo em que está envolvido. Como os Processos de maior ocorrência são os Materiais e Relacionais, os Participantes ativos são Ator (40\% e 44\%), Portador (18\% e 16\%) e Identificado (7\% na textualização e retextualização).

Se os paratextos realmente podem influenciar a leitura e a recepção do texto, então a expectativa do leitor seria de encontrar um Participante "translator/tradutor", envolvido majoritariamente em Processos Materiais, Relacionais e Verbais, participando como Ator, Identificado, Portador e Dizente. De fato, em uma proporção diferenciada, essas 4 representações são as formas mais ocorrentes de configuração do Participante "translator/tradutor". Entretanto, no interior da obra, coincidindo com o número de ocorrência do Participante Dizente e Identificado, observa-se a ocorrência do Participante Experienciador, não mencionado em nenhum dos paratextos. Essa característica mostra que, no interior da obra, tanto os itens lexicais "translator" como "tradutor" são representados não apenas como entidades que agem realizando ações relacionadas ao seu trabalho de tradutor (realizadas pelos Processos Materiais), sendo relacionados a personagens que fizeram história (realizados pelos Processos Relacionais) ou comunicando (realizado pelo Processo Verbal), mas também tomando decisões, refletindo e participando cognitivamente de atividades intelectuais (realizado pelos Processos Mentais).

\section{Reflexões finais}

A pergunta de pesquisa que motivou o trabalho foi baseada na afirmativa de Munday (2002) de que geralmente na tradução há padrões de transitividade diferentes daqueles do texto original. Desenvolvida na interface entre a LSF, ETBC e os ET, esta pesquisa buscou verificar se de fato ocorriam (e em caso positivo, como 
e onde) novas configurações no perfil ideacional da figura do tradutor, dentro do corpus bilíngue de pequena dimensão, composto pelo Prefácio, Introdução e os 5 primeiros capítulos de Translator Through History e Os Tradutores na História.Para tanto, realizouse um levantamento quantitativo dos padrões emergentes dos Participantes "translator", na textualização, e "tradutor", na retextualização, e dos Processos em que estavam envolvidos, tanto nos paratextos quanto no corpo dos textos em relação tradutória: tais itens constituíram o objeto de análise, em contextos em que exerceram função de núcleos de grupos nominais e de Participantes em Processos, sendo também observados e descritos em relação coesiva de referência, dentro do Complexo Oracional. O método adotado para processamento dos dados foi baseado em Fernandes (2004), em que se utilizaram procedimentos e ferramentas dos estudos baseados em corpus: alinhamento, rotulação por meio do CROSF15 e concordância com a utilização do software WordSmith Tools.

Foi tomada a decisão metodológica de se separar o corpo da obra de seus paratextos, uma vez que os últimos são considerados um tipo textual diferenciado, por seu papel de mediadores entre o texto e o leitor, o que lhes confere o potencial de serem construídos visando ao impacto na recepção do texto, seja ele original ou tradução (cf. Genette, 1982 e Koava, 1996). Comparar, então, a contracapa da textualização e da retextualização com o corpus do texto possibilitou cotejar a representação do Participante "translator/tradutor" construída nos paratextos com aquela construída no corpo das obras analisadas.

Os resultados da análise evidenciaram que os padrões emergentes nos paratextos são parcialmente análogos aos padrões do corpo do texto. Em ambas as obras, os Participantes "translator" (na textualização) e Participante "tradutor" (na retextualização) emergem majoritariamente nas funções Ator, Identificado, Portador e Dizente.

Um dado interessante e inesperado observado nos paratextos foi a -não ocorrência de "translator/tradutor" como Participante de Processos Mentais, isto é, Experienciador. Isso leva à leitura 
de que, inicialmente, nos paratextos, o "translator/tradutor" não é realizado como uma entidade que reflete sobre os acontecimentos e/ou que toma decisões a respeito deles, mas como uma entidade que realiza atividades relacionadas à sua tarefa profissional, enquanto Ator, tais como: inventar alfabetos, colaborar para o desenvolvimento e enriquecimento das línguas, estimular a formação das literaturas nacionais, agir em instâncias do poder, disseminar o conhecimento técnico e científico, difundir religiões e escrever dicionários; nessa configuração, é associado a figuras que participaram da construção da história, como um Portador e Identificado, sendo qualificado por seus feitos. Apenas no corpo do texto, observa-se que a intervenção dessas figuras na história das civilizações se dá também em decorrência de atividades intelectuais e cognitivas, intrínsecas à carga semântica dos Processos Mentais e do Participante Experienciador.

No que tange a relação entre a análise do corpo do texto da textualização com a análise do corpo do texto da retextualização, foi possível verificar que os padrões emergentes no primeiro são análogos aos emergentes no segundo. Isto é, "translator" e "tradutor" são configurados principalmente como Participantes ativos, sendo predominante, em ambos os textos, a ocorrência de tais itens lexicais como Ator, envolvido no Processo Material, Portador e Identificado, no Processo Relacional, como Experienciador, no Processo Mental e como Dizente, no Processo Verbal. Em consonância com a análise dos paratextos, houve ocorrências pouco significativas de Processos Comportamentais e Existenciais. A diferença de tais configurações entre a textualização e a retextualização está relacionada possivelmente à ocorrência de novas construções nos padrões de transitividade na tradução. Na retextualização, em comparação com a textualização, o item lexical "tradutor" foi $4 \%$ mais representado como Ator e $1 \%$ menos representado como Experienciador e Portador. Essa diferença na construção da figura do tradutor permite concordar com Munday (2002); no entanto, o perfil quantitativo de ocorrência dessas novas construções não permite 
afirmar que alterações significativas ocorrem na representação do Participante "tradutor" na obra retextualizada.

Como palavra final, cumpre ressaltar que o estudo possibilitou corroborar a produtividade da interface entre a LSF, metodologias de corpus e ET, na análise de textualizações e suas retextualizações para determinar "aspectos importantes que têm sofrido mudanças na tradução" (Munday, 2002, p.89). Reitera-se, assim, o potencial do arcabouço teórico e metodológico proposto, que se mostrou capaz de possibilitar análises comparativas - calcadas em bases empíricas - de aspectos essenciais dos significados selecionados e realizados nos dois textos. Neste sentido, o estudo realizado cumpriu seu objetivo maior de contribuir para o entendimento das formas de representação do tradutor - em termos das premissas semióticas de LSF - no próprio ambiente da tradução, apresentando um modelo teórico-metodológico robusto para proceder a uma análise de textos em relação tradutória.

\section{Notas}

1. Este artigo resulta da pesquisa de mestrado defendida em 2006 por Lilian Jurkevicz Fleuri, orientada por Dra. Maria Lúcia Vasconcellos e co-orientada por Dra. Adriana Pagano, no Programa de Pós-Graduação em Estudos da Tradução da Universidade Federal de Santa Catarina, intitulada $O$ Perfil Ideacional dos Itens Lexicais Translator/Tradutor em Translators Through History e em Os Tradutores Na História.

2. Tradução de Sérgio Bath (2003).

3. Tradução nossa (todas as traduções neste artigo são de nossa autoria): "These data on micro-structural strategies should lead to a renewed con- 
frontation with macro-structural strategies, and hence to their consideration in terms of the broader systemic context."

4. A seção 2 deste artigo explora o conceito de Complexo Oracional segundo definições de Halliday (1994, 2004).

5. O "Complexo Oracional" é um conjunto de orações conectadas umas às outras por meio de relações lógico-semânticas (Halliday e Matthiessen, 2004, p.363).

6. Os elementos coesivos analisados são apenas os que se encontram no interior do Complexo Oracional que consta o item lexical "translator/tradutor", tais como os pronomes e elipses que se relacionam aos item lexical mencionado.

7. Os exemplos foram retirados do livro Os Tradutores na História.

8. A tabela do CROSF15, utilizada nessa pesquisa, encontra-se anexada em Fleuri (2006).

9. A leitura dos dados coletados deu-se à luz das categorias do sistema de Transitividade (Halliday e Mathiessen, 2004, p.170-171) e do significado de cada Processo. Assim, Processo Material é entendido como Processo relacionado às experiências externas e aos Processos do mundo externo, que representam ações físicas de coisas acontecendo ou sendo criadas, mudanças físicas, realizações e atuações. Processos Mentais, por sua vez, estão relacionados às experiências internas, que são em parte "um tipo de resposta às experiências externas, no momento em que são memorizadas, que se reage emocionalmente a elas, que se reflete sobre elas, e, em parte uma consciência de nosso estado de ser" (idem, ibdem). Processos Relacionais "relacionam um fragmento de experiência a outro" (idem, ibidem), identificando e classificando elementos; Processos Relacionais atuam no mundo das relações abstratas, relacionando dois ou mais elementos em uma conexão de atribuição de qualidades, valores, posses e identidades, identificando, classificando e simbolizando coisas e seres. Processos Verbais representam as "relações simbólicas construídas na consciência humana e configuradas em forma linguística, como dizer e significar" (idem, ibdem). Segundo Martin, Matthiessen e Painter (1997), "as orações Verbais representam Processos de dizer"; mas essa categoria não inclui apenas os diferentes modos de se dizer algo, tais como perguntar, comandar, indicar etc., dela participando, também, os Processos semióticos que não são necessariamente verbais, tais como: mostrar, apontar, indicar etc. 
10. vd. Fleuri, 2006, p.71-86 para detalhes do modo como esta ferramenta foi utilizada e do modo de rotulação feito por meio do CROSF15.

\section{Tradução nossa.}

12. Adota-se, neste trabalho, o termo 'ativo' para descrever a posição do Participante em relação ao Processo, quanto à realização da ação envolvida, com base em Thompson (1996, p.88-89). O que nos interessa é distinguir entre um papel funcional de "Ator", ou "Dizente", ou "Experienciador", ou "Portador", etc. em oposição a papéis funcionais de "meta" (Participante a quem a ação do "Ator" é direcionada), ou "Receptor" (Participante a quem a mensagem é direcionada), ou "Fenômeno" (Participante que sofre a cognição do "experienciador"), e assim por diante. Para fins deste trabalho, adotamos, por extensão e analogia, a distinção entre "ativo" e “passivo" para explicar a natureza e abrangência da 'ação' do Participante.

13. Os dados referente a essa frequência foram extraídos através do WordSmith Tools, com o auxílio da ferramenta WordList, tomando como texto de pesquisa a lista de Processos elaborada exclusivamente para este fim (cf. Fleuri, 2006). Estes dados foram confirmados através da observação das ocorrências obtidas por meio do Concord.

\section{Bibliografia}

BAKER, M. (1992). In Other Words: A coursebook on Translation. London: Routledge.

BAKER, M. (1995). Corpora in Translation Studies: An Overview and Some Suggestions for Future Research. Amsterdam: John Benjamins.

BAKER, M. (1998). Encyclopedia of Translation Studies. London: Routledge. 
BELL, R. (1991). Translation and translating: theory and practice. London: Longman.

DESLILE, J.; WOODSWORTH, J. (1995). Translators through history. Montreal: John Benjamins.

DESLILE, J.; WOODSWORTH, J. (2003). Os tradutores na história. (S. Bath, Trans.) São Paulo: Ática.

EGGINS, S. (1994). An introduction to systemic-functional linguistics. London: Pinter.

FEITOSA, M. (2005). Uma proposta de anotação de corpora paralelos com base na linguistica sistêmico-funcional. Belo Horizonte: Programa de Pós-Graduação da Faculdade de Letras/UFMG.

FERNANDES, L. (2004). Translating children literature: a corpus-based study of proper names. Florianópolis: Programa de Pós-Graduação em Letras Inglês/ UFSC.

FLEURI, L. J. (2006). O perfil ideacional dos itens lexicais translator/tradutor em "Translator through history". Florianópolis: Programa de Pós-Graduação em Estudos da Tradução/UFSC.

GALLINA. (1992). "Cohesion and the systemic functional approach to text: application to political speeches and the significances to simutaneous interpretation". Interprete's New Letter, p. 62-71.

GENETTE, G. (1982). Palimpsests: literature in the second degree (Stages). Nebraska: University of Nebraska Press.

GOVEIA, C.; BARBARA, L. (2003). Tema e estrutura temática em PE e PB: um estudo contrastivo das traduções portuguesa e brasileira. São Paulo/Liverpool: LAEL - Pontífica Universidade Católica/ AESLU - University of Liverpool. 
HALE, S. (1997). The treatment of register variation in court interpreting. The translator, v.3(1), p. 39-54.

HALLIDAY, M. A. (1985/1994/2004). An introduction to functional grammar. London: Arnold.

HALLIDAY, M. A. (2004b). The language of science. (J. J. Webster, Ed.) New York: MPG Bookes Ltd.

HALLIDAY, M. A.; HASSAN, R. (1989). Language, context, and text: aspects of language in a social-semiotic perspective. Hong Kong: Oxford University Press.

HALLIDAY, M. A.; MATHIESSEN, C. (2004). An introduction to functional grammar. London: Arnold.

HATIM, B.; MASON, I. (1990) Discourse and the translator. London: Longman.

JOHNS, T. (1992). "It is resented initially: linear dislocation e inter-language strategies in Brazilian academic abstracts in english and Portuguese". Ilha do Desterro, v.0, n.27 .

KOVALA, U. (1996). "Translation, paratextual mediation and ideological closure”. Target (8:1). Amsterdam: John Benjamins. p. 119-147.

LEUVEN-ZWART, Van (1989/1990): “Translation and original: similarities and dissimilarities I e II”. Target 1(2), 151-181, Target 2(1), 69-95

MALMKJAER, K. (1998). Love thy neighbor: will parallel corpora endear linguists to translators? In Meta, XLIII, 4. Available from:http://www.erudit.org/ revue/meta/1998/v43/n4/003545ar.html . Retrieved on 8 November, 2007.

MALMKJAER, K. (2005). Linguistics and the language of translation. Edinburgh: Edinburgh University Press. 
MARTIN, J. R.; MATHIESSEN, C. M.; PAINTER, C. (1997). Working with functional grammar. New York: Arnold.

MUNDAY, J. (2002). Systems in translation. A systemic model for descriptive translation studies. In T. HERMANS, Crosscultural transgressions, research models in translation studies, II. Historical and ideological issues. Manchester: St. Jerome, p. 76-92

NEWMARK, P. (1988). A textbook of translation. New York: Prentice-Hall International.

OLOHAN, M. (2004). Introducing corpora in translation studies. London/New York: Routledge.

PAGANO, A. S.; VASCONCELLOS, M.L. (2005). Explorando interfaces: Estudos da Tradução, Linguística Sistêmico-Funcional e Linguística de corpus. In: ALVES et al. Competência em tradução: cognição e discurso. Belo Horizonte/ MG: Editora da UFMG.

SARDINHA, T. B. (2004). Linguistica de corpus. Barueri (SP): Manole.

SCOTT, M. (1999). WordSmith Tools. Oxford University Press.

SINCLAIR, J. M. (2001). Preface. In M. Ghadessy, A. HENRY, e R. ROSEBERRY, Small corpus studies and ELT. Theory and practice (pp. vii-xv). Amsterdam: John Benjamin.

THOMPSON, G. (1996/2004). Introducing functional grammar. Great Britain: Arnol.

TYMOCZKO, M. (2002). Connecting the two infinite orders: research methods in translation studies. Crosscultural transgressions: research models in translation studies II: Historical and ideological issues. Ed. Theo Hermans. Manchester: St. Jerome Publishing. 
GORP, H.V. (2006). On describing translation. Functional approaches to culture and translation: selected papers by Jose Lambert. (D. DELABASTITA, L.D'HULST e R. MEYLAERTS, Eds.). Amsterdam/Philadelfia.

VASCONCELLOS, M. L. (2009). Systemic functional translation studies (SFTS): The theory travelling in Brazilian environments. D.E.L.T.A, Volume Especial, n. 25, p. 585-607.

ZHU, C. (1993). Structure of meaning (SOM): towards a three-dimension perspective on translating between Chinese and English. Nottingham: University of Nottingham. 